\title{
Respuesta bioquímica de plántulas de maíz (Zea mays L.) a diferentes condiciones de temperaturas nocturnas
}

\section{Biochemical response of maize (Zea mays L.) seedlings to different conditions of nighttime temperatures}

\section{HERMANN RESTREP01, 4 \\ MANUEL IVAN GÓMEZ1 \\ ALFONSO GARZÓN² \\ LADY MANRIQUE ${ }^{3}$ \\ FRANCISCO ALZATE ${ }^{3}$ \\ JESÚS LÓPEZ ${ }^{3}$ \\ ADALBERTO RODRÍGUEZ $Z^{3}$}

Plantación de maíz en

Puerto Gaitán (Meta, Colombia).

Foto: F. Alzate

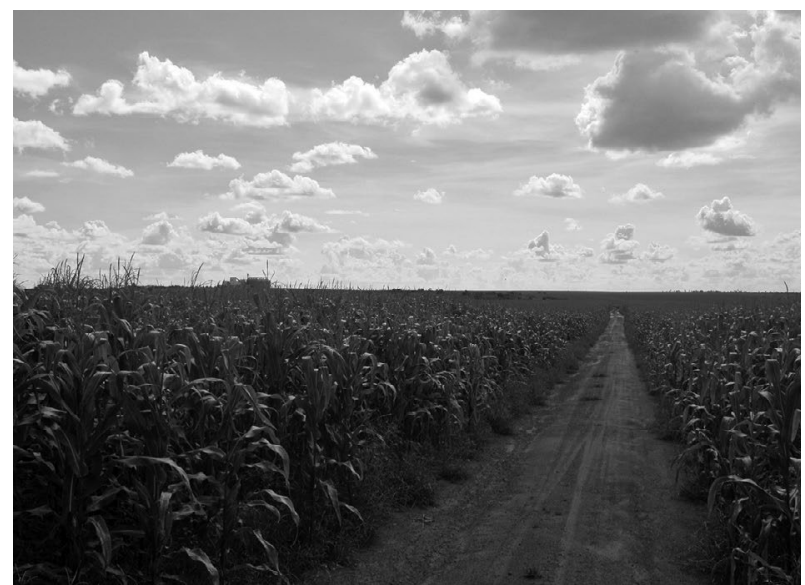

\section{RESUMEN}

El maíz en Colombia es cultivado en diferentes pisos térmicos, permitiendo la siembra de un mismo material en un rango amplio de temperaturas. En regiones de clima cálido $(\leq 1.000 \mathrm{mnsm})$ y clima frío $(\geq 2.000 \mathrm{msnm})$ pueden existir daños al cultivo por altas o bajas temperaturas nocturnas en ciertos periodos del año. Para medir los efectos fisiológicos del estrés por temperaturas altas y bajas en maíz variedad Porva fue desarrollado un experimento durante el primer semestre del año 2013 con temperaturas bajas de $5^{\circ} \mathrm{C}$ y altas de $25^{\circ} \mathrm{C}$ durante 36 horas nocturnas y consecutivas acumuladas en la etapa V3 de las plantas. En hojas de maíz se midieron variables de: i) pérdida de electrolitos; ii) fluorescencia de la clorofila a (Fv/Fm); iii) prolina y iv) malondialdehído (MDA); inmediatamente se terminó el estrés por calor o frío en las plántulas de maíz. Los resultados mostraron que las plantas de maíz en la etapa V3 (tres hojas) son más afectadas por el frío que el calor en términos de integridad de las membranas celulares de las hojas. También, se encontró un aumento de la prolina en las hojas en condiciones de calor $(+57,6 \%)$ o frío (+4,3\%) y una estabilidad en la producción de MDA y la fluorescencia de la clorofila a en las hojas, a pesar del estrés por frío o calor. Estos resultados indican que en las zonas frías de Colombia durante las épocas de heladas, las membranas celulares son el primer componente estructural afectado en las hojas del maíz. Este trabajo es una guía para encontrar prácticas agronómicas en el cultivo de maíz, que limiten la peroxidación de membranas celulares de plantas durante condiciones ambientales de temperaturas bajas.

\footnotetext{
Palabras clave adicionales: fluorescencia, calor, frío, prolina, malondialdehido, pérdida de electrolitos.

Facultad de Ciencias Agrarias, Departamento de Agronomía, Universidad Nacional de Colombia, Bogotá (Colombia).

2 Facultad de Ciencias Agrarias, Universidad Nacional de Colombia, Bogotá (Colombia).

3 Programa de Maestría en Ciencias Agrarias, Facultad de Ciencias Agrarias, Universidad Nacional de Colombia, Bogotá (Colombia).

4 Autor para correspondencia. hrestrepod@unal.edu.co
} 


\section{ABSTRACT}

Maize is grown from 0 to 3,000 $\mathrm{m}$ a.s.1. in Colombia, meaning that plants are exposed to a wide range of temperatures. In warm and cold regions of Colombia ( $\leq 1,000$ and $\geq 2,000 \mathrm{~m}$ a.s.l., respectively), physiological disorders can be observed in maize crops due to the high or low night temperatures in certain periods of the year. 'Porva' maize plants were exposed to 5 and $25^{\circ} \mathrm{C}$ (the low and high nighttime temperatures, respectively); meanwhile, the control plants were maintained under growing conditions during the experiment $\left(15^{\circ} \mathrm{C}\right)$. The temperature treatments were carried out in the maize plants during the V3 stage. Physiological variables such as lipid peroxidation (MDA content), proline, chlorophyll fluorescence and membrane permeability damage resulting from electrolyte leakage were estimated. The results showed that the proline content in the maize leaves was higher in the plants submitted to high nighttime temperatures when compared to plants exposed to $5^{\circ} \mathrm{C}$ for 36 hours. In addition, the nighttime treatments $\left(5\right.$ and $25^{\circ} \mathrm{C}$ ) increased the electrolyte leakage in the maize leaves. Changes due to temperature treatments were not observed for MDA content and Fv/ Fm ratio. These results seem to indicate that the cell walls are the first component to be affected in maize leaves by low temperatures in the cold regions of Colombia. Furthermore, this study is a guide for finding agronomic techniques in maize crops that ameliorate the negative effects of cell wall damage caused by the membrane permeability damage resulting from cold stress.

Additional key words: fluorescence, heat, cold, proline, malondialdehyde, electrolyte leakage.

Fecha de recepción: 08-07-2013

Aprobado para publicación: 31-10-2013

INTRODUCCIÓN

El maíz (Zea mays L.) es uno de los granos alimenticios más importante entre los cereales a nivel mundial por su producción de 795.935.000 t en las temporadas 2009-2011 y es el cultivo transitorio más sembrado en Colombia con 144.173 ha en 2012 (DANE, 2013). El 90\% de la producción mundial corresponde a maíz amarillo y el 10\% restante a maíz blanco (Fenalce, 2010). El maíz ocupa el segundo lugar en área de siembra con alrededor de 140.000 .000 ha en 135 países y se comercializan en el mercado internacional más de 90 millones de toneladas (Fenalce, 2010). En Colombia la diversidad de los ambientes bajo los cuales se siembra es mayor que la de cualquier otro cultivo y aunque se originó en la zona tropical y subtropical, como una planta de excelentes rendimientos, en la actualidad se cultiva desde los $300 \mathrm{msnm}$ hasta los $3.000 \mathrm{msnm}$ (Fenalce, 2010).
Squire (1990) menciona que el maíz por estar cultivado en diferentes ambientes, está sometido a cambios súbitos de temperatura, donde los incrementos o descensos en esta pueden traer efectos adversos para la planta. Paulsen (1994) observó que la fotosíntesis en maíz disminuye a temperaturas mayores de $40^{\circ} \mathrm{C}$, principalmente a causa del daño a las membranas, lo que produce pérdida de electrolitos y desequilibrio de las relaciones hídricas, fotoinhibición, acumulación de azúcares, prolina, producción de especies reactivas de oxigeno (ROS) y malondialdehído (MDA) en hojas. En respuestas a las altas temperaturas, la planta para mantener su desarrollo coloca en marcha estrategias para su protección de los tejidos, como la formación de proteínas de choque térmico y enzimas detoxificadoras (Pollock et al., 1993). Los mecanismos de tolerancia al estrés 
ocasionado por altas temperaturas se han identificado en el maíz de acuerdo con sus características genéticas como expresión de tolerancia térmica adquirida (Jorgensen y Nguyen, 1995).

El maíz también es un cultivo sensible al frío y sufre daños a temperaturas entre 0 y $10^{\circ} \mathrm{C}$ si está expuesto a la luz adecuada y a temperaturas entre 10 y $15^{\circ} \mathrm{C}$ cuando está expuesto a la luz intensa, dependiendo de los cultivares. Los efectos de las bajas temperaturas se manifiestan sobre las funciones de enzimas y propiedades de las membranas y estos efectos como en las altas temperaturas se expresan en la reducción de la fotosíntesis, el crecimiento, la extensión de las hojas y la absorción de agua y nutrientes minerales (Miedema, 1982). Las temperaturas bajas pueden también resultar en un desarrollo radical anormal y en la pérdida de turgencia en hojas (Aloni y Griffith, 1991).

La fotosíntesis es afectada por las bajas temperaturas, especialmente en presencia de luz intensa. El umbral para un daño irreversible al sistema fotosintético es de $1,5 \mathrm{~d}$ a $10^{\circ} \mathrm{C}$ para el maíz de zona templada y con luz intensa (Miedema, 1982); estas condiciones, sin embargo, raramente se encuentran en zonas tropicales. Más importantes son los efectos reversibles de las bajas temperaturas nocturnas sobre el sistema fotosintético; algunos híbridos para zona templada han mostrado una recuperación más rápida de la actividad fotosintética después de un periodo frío que otros híbridos más antiguos, lo cual puede ser debido a una más eficiente eliminación de los radicales libres que ocurren por el daño a las membranas (Tollenaar et al., 1993).

El frío también afecta la translocación de los metabolitos y en las especies sensibles tales como los cultivares de maíz de zonas bajas, estos procesos se reducen a temperaturas por debajo de $10^{\circ} \mathrm{C}$. La translocación de los carbohidratos disminuye sensiblemente durante el período nocturno y lleva a la acumulación de almidón en los cloroplastos, lo cual reduce la fotosíntesis. Esta explicación puede parecer muy simple, pero es evidente que tanto las fuentes como los vertederos son afectados por las bajas temperaturas (Wardlaw, 1993). Por tal motivo, el objetivo de la presente investigación fue evaluar el efecto de tres condiciones de temperatura sobre plántulas de maíz mediante la estimación de parámetros bioquímicos y fisiológicos como producción de prolina, malondialdehído (MDA), pérdida de electrolitos y fluorescencia de la clorofila (Fv/ Fm) en hojas, con el fin de conocer la respuesta del cultivo de maíz en estados tempranos a condiciones extremas de temperaturas.

\section{MATERIALES Y MÉTODOS}

Semillas de maíz variedad Porva sembrado en macetas plásticas de $500 \mathrm{~mL}$ de volumen conteniendo turba rubia con nutrientes (KlasmannDeilmann $\mathrm{GmbH}$, Geeste, Alemania) como sustrato, durante el primer semestre del año 2013 bajo condiciones de invernadero de $15^{\circ} \mathrm{C}$, fotoperiodo de $12 \mathrm{~h}$ y humedad relativa del $70 \%$ fueron crecidas hasta la etapa V3 (tres hojas) para evaluar los efectos fisiológicos del estrés por frío $\left(5^{\circ} \mathrm{C}\right)$ y calor $\left(25^{\circ} \mathrm{C}\right)$. El experimento consistió en un diseño completamente al azar con tres tratamientos de temperaturas (control a $15^{\circ} \mathrm{C}$; frío con $5^{\circ} \mathrm{C}$ durante $36 \mathrm{~h}$ nocturnas acumuladas; calor con $25^{\circ} \mathrm{C}$ durante $36 \mathrm{~h}$ acumuladas nocturnas). Las anteriores temperaturas fueron seleccionadas debido a su frecuencia de ocurrencia en las zonas productoras de maíz en Colombia. Durante los tratamientos de estrés térmico, las plántulas entre las 8:00 p.m. hasta las 8:00 a.m. por $3 \mathrm{~d}$ consecutivos fueron colocadas en neveras a $25^{\circ} \mathrm{C}$ (calor) y $5^{\circ} \mathrm{C}$ (frío), mientras que el testigo permaneció a una temperatura nocturna de $15^{\circ} \mathrm{C}$. En la mañana después de las 8:00 a.m., todas las plántulas del experimento fueron retornadas a las condiciones anteriormente mencionadas del invernadero. Cada tratamiento se repitió cuatro veces con una unidad experimental defi- 
nida como una plántula. Después del periodo de estrés, las plantas de maíz fueron utilizadas para determinación de fluorescencia de la clorofila (Fv/Fm), pérdida de electrolitos (\%), producción de prolina y acumulación de malondialdehido (MDA). Los resultados fueron analizados con el programa estadístico SAS 9.0 (SAS Institute Inc., Cary, NC). Cuando el análisis de varianza (Anava) reportó diferencias entre tratamientos, se procedió a realizar la prueba estadística de Tukey $(P \leq 0,05)$ para comparación de medias.

\section{Cuantificación de Fv/Fm}

La clorofila fluorescente se midió con el fluorómetro (Handy Pea, Hansatech Instruments, Norfolk, UK) mediante la ubicación de clips en los tejidos foliares de las plantas para someterlas a oscuridad durante 15 min y posteriormente, la medición fue realizada sobre una hoja expandida y fisiológicamente activa (hoja número 2).

\section{Cuantificación de electrolitos}

Para la evaluación de electrolitos se pesaron 0,3 $\mathrm{g}$ de material vegetal fresco (hojas), las cuales se lavaron levemente con agua desionizada, se cortaron en trozos de $1 \mathrm{~cm}$ de largo y se colocaron los trozos en un tubo de ensayo, adicionando 30 $\mathrm{mL}$ de agua desionizada, se agitaron los tubo de ensayo en un vortex durante 1 min. Posteriormente se incubaron los tubos en baño de María a una temperatura de $30^{\circ} \mathrm{C}$ durante $2 \mathrm{~h}$. Con el conductímetro se midió la conductividad eléctrica inicial $\left(E_{1}\right)$, posteriormente se incubaron nuevamente en el baño de María, durante 15 min a una temperatura de $100^{\circ} \mathrm{C}$, para extraer todos los electrolitos liberados. Con el conductímetro marca Oak Ton PC 700 (Singapur) se medió la conductividad eléctrica final $\left(\mathrm{EC}_{2}\right)$. Se calculó el porcentaje de electrolitos con la siguiente fórmula:

$\%$ Electrolitos $=\left(\frac{E C_{1}}{E C_{2}}\right) \times 100$

\section{Determinación de malondialdehido (MDA)}

Se pesaron $0,3 \mathrm{~g}$ de material vegetal fresco (hojas), posteriormente se homogenizó el material vegetal en un mortero agregándole $3 \mathrm{ml}$ de ácido tricloroacético al $0,1 \%$, se filtró la muestra homogenizada con papel filtro, de la cual se extrajo $1 \mathrm{~mL}$ y se depositó en un tubo de ensayo al cual se le agregó $3 \mathrm{~mL}$ ácido tricloroacético 10\% en $0,65 \%$ de ácido tiobarbitúrico (p/v). Se incubó la muestra en baño de María durante 25 min a $95^{\circ} \mathrm{C}$ y al terminar se detuvo la reacción en hielo. Posteriormente las muestras se centrifugaron durante 25 min a 10.000 g. El sobrenadante de cada muestra se depositó en celdas para medir la absorbancia a $532 \mathrm{~nm}$ y $600 \mathrm{~nm}$, usando como blanco una muestra de la mezcla entre $1,5 \mathrm{~mL}$ de ácido tiobarbitúrico 0,65\% y 1,5 mL de ácido tricloroacético $10 \%$. Se calculó en contenido de MDA para cada tratamiento de acuerdo a la siguiente fórmula:

MDA equivalente $\left(\frac{m m o l}{m L}\right)=\left[\frac{\left(A_{532}-A_{600}\right)}{155000}\right] 10^{6}(2)$

\section{Determinación de prolina}

Se pesaron en promedio 0,15 a $0,20 \mathrm{~g}$ de material vegetal fresco, el cual se homogenizó en $10 \mathrm{~mL}$ de solución acuosa de ácido sulfosalicílico $3 \%$ y el homogenizado se filtró a través de papel whatman. Dos $\mathrm{mL}$ del filtrado se hicieron reaccionar con $2 \mathrm{~mL}$ de ácido ninhidrina y 2 $\mathrm{mL}$ de ácido acético glacial en un tubo de ensayo durante $1 \mathrm{~h}$ a $100^{\circ} \mathrm{C}$, la reacción se detuvo en un baño con hielo. La mezcla de extrajo con $4 \mathrm{~mL}$ de tolueno, se mezclaron vigorosamente con un vortex durante $20 \mathrm{~s}$. El cromóforo que contiene tolueno se aspiró de la fase acuosa, se calentó a temperatura ambiente y se leyó la absorbancia a $520 \mathrm{~nm}$ utilizando tolueno como blanco. La concentración de prolina se determinó a partir de una curva patrón previamente establecida y se calculó sobre una base de peso fresco de acuerdo a la siguiente fórmula: 
$\left(\frac{\mu \text { mol prolina }}{\text { g material vegetal fresco }}\right)=\left[\frac{\left(\mu \mathrm{g} \frac{\text { prolina }}{m L} \times m L \text { tolueno }\right)}{115,5 \mu \mathrm{g} / \mu \mathrm{mol}}\right]$

\section{RESULTADOS Y DISCUSIÓN}

\section{Pérdida de electrolitos}

Para conocer la influencia de las temperaturas extremas nocturnas en plántulas de maíz sobre la integridad de las membranas celulares, fue medida la pérdida de electrolitos (\%) después de las $36 \mathrm{~h}$ acumuladas de temperaturas en las plantas a $5^{\circ} \mathrm{C}$ (frío), $15^{\circ} \mathrm{C}$ (control) y $25^{\circ} \mathrm{C}$ (calor). Los resultados se muestran en la figura 1 .

Los resultados indican que la temperatura extrema de $5^{\circ} \mathrm{C}$ por $36 \mathrm{~h}$ nocturnas acumuladas aumentó la salida de electrolitos de la célula por pérdida de integridad de las membranas, mientras que temperaturas de $25^{\circ} \mathrm{C}$ acumuladas en la noche no tuvieron efecto significativo sobre la integridad de las membranas celulares. Gong et al. (2001), en un estudio sobre plántulas de maíz sometidas a estrés abiótico por calor, frío, sequía y salinidad, encontraron que la pérdida de electrolitos cuando las plantas fueron estresadas por calor se presentó solo después de 90 h, resultados coherentes para este experimento, donde a las $36 \mathrm{~h}$ acumuladas con temperaturas nocturnas de $25^{\circ} \mathrm{C}$ las membranas celulares permanecieron estables en su integridad y permeabilidad en comparación con el tratamiento control. En contraste, los trabajos en maíz reflejan que las temperaturas bajas causan una rápida disminución de la integridad de la membrana celular, generando una fuga de electrolitos (Mahajan y Tuteja, 2005; Franciszek et al., 2002; Gong et al., 2001), resultados consistentes con esta investigación. Esta pérdida de integridad de las membranas celulares es generada por la peroxidación lipídica bajo condiciones de estrés a causa de las especies reactivas de oxígeno ROS que actúan sobre radicales libres $\mathrm{LOO}^{-}$y $\mathrm{COO}^{-}$de lípidos de las membranas (Zhu, 2002; Ishitani et al., 2000).

También, los resultados indican que las condiciones de frío causan mayor estrés sobre el maíz que condiciones de alta temperatura. Al respecto, el

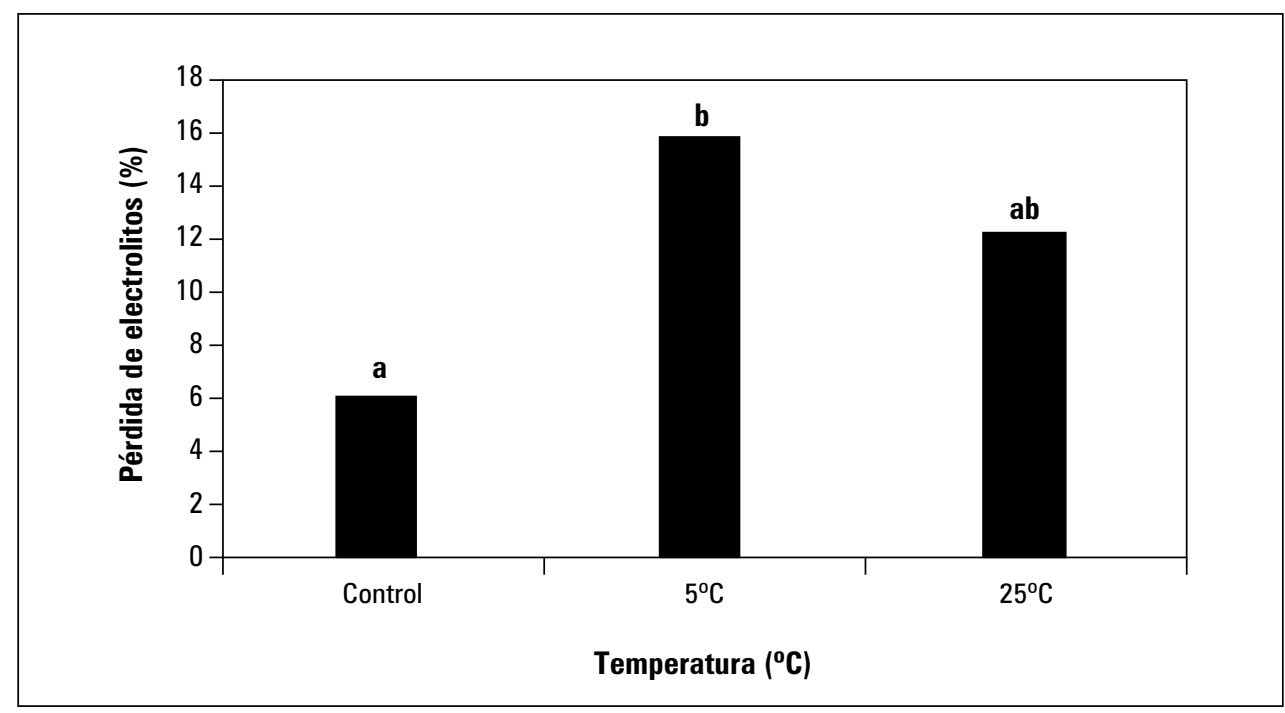

Figura 1. Pérdida de electrolitos en hojas de plantas de maíz (Zea mays L.) en la etapa V3 bajo condiciones de estrés por temperaturas extremas. Control: temperatura nocturna normal $\left(15^{\circ} \mathrm{C}\right)$, frío: temperatura nocturna acumulada por $36 \mathrm{~h}$ de $5^{\circ} \mathrm{C}$, calor: temperatura nocturna acumulada por $36 \mathrm{~h}$ de $25^{\circ} \mathrm{C}$. Promedios con letras distintas indican diferencia significativa según la prueba de Tukey $(P \leq 0.05)$. 
maíz por ser una planta tropical $\mathrm{C}_{4}$ adaptada a condiciones de alta temperatura y luz presenta mayor sensibilidad a bajas temperaturas (menor a $15^{\circ} \mathrm{C}$ ), resultando en una prematura senescencia de las hojas, inhibición de la asimilación de $\mathrm{CO}_{2}$ y disminución en el transporte de electrones (Foyer et al., 2002). Una disminución en el transporte de electrones de la fotosíntesis en el maíz causa un incremento en la producción de especies reactivas de oxigeno (ROS) como oxígeno singlete, anión superóxido, peróxido de hidrógeno y radicales hidroxilo, que causan peroxidación de lípidos de membranas celulares (Foyer y Harbinson, 1999; Foyer y Harbinson, 1994). La peroxidación lipídica de membranas causa un aumento de su permeabilidad y una fuga de electrolitos de la célula (Hansen y Dörffling, 1999; Janowiak y Dörffling, 1996; Duchoslav y Fracheboud, 1994; Li, 1994; Capell y Dörffling, 1993; FloresNimedes et al., 1993; Tantau y Dörffling, 1991; Ludewig et al., 1988), que fue medida de manera significativa en las plantas de maíz de baja temperatura en comparación con las de control.

\section{Fluorescencia de la clorofila a (Fv/Fm)}

La fluorescencia de la clorofila a medida que la relación entre $\mathrm{Fv} / \mathrm{Fm}$ fue determinada para las plántulas de maíz estresadas por calor y frío para conocer la influencia de las temperaturas extremas sobre la máxima eficiencia cuántica del fotosistema II. Los resultados, presentados en la figura 2 no arrojaron diferencias significativas entre los tratamientos, indicando que la eficiencia máxima del fotosistema II (Fv/Fm) no se altera a las $36 \mathrm{~h}$ acumuladas en plántulas de maíz con temperaturas extremas nocturnas de $5^{\circ} \mathrm{C}$ o $25^{\circ} \mathrm{C}$. Franciszek et al. (2002), en plántulas de maíz bajo estrés por bajas temperaturas $\left(4^{\circ} \mathrm{C}\right)$ al tercer día, solo detectaron una caída en la relación $\mathrm{Fv} / \mathrm{Fm}$ menor del 10\% y correspondió a los primeros estados en el aumento lineal de la fluorescencia de la clorofila a (menor Fv/ Fm) de las plantas de maíz. Aroca et al. (2001) midieron parámetros fotosintéticos y mecanismos de protección antioxidante en variedades de maíz sensibles y resistentes al frío, encontrando que $3 \mathrm{~d}$ después del estrés por bajas temperaturas $\left(5^{\circ} \mathrm{C}\right)$ tanto en las variedades sensibles como resistentes se presentó una reducción significativa del parámetro $\mathrm{Fv} / \mathrm{Fm}$, indicando un aumento de la fluorescencia de la clorfila a. Sin embargo, los autores mencionan que la recuperación del parámetro Fv/Fm a sus niveles normales ocurre en términos de horas. En el experimento sobre el efecto de las temperaturas bajas $\left(5^{\circ} \mathrm{C}\right)$ en maíz Porva, la medición de la fluorescencia de la clorofila se realizó $2 \mathrm{~h}$ después bajo temperaturas ambientales normales $\left(15^{\circ} \mathrm{C}\right)$, situación que podría explicar por qué entre los tratamientos de frío y calor no fueron expresadas diferencias para la fluorescencia de la clorofila (Fv/Fm).

\section{Prolina}

La prolina es un osmolito compatible que ha mostrado un efecto crioprotector en plantas bajo estrés por frío (Mahajan y Tuteja, 2005; Xin y Browse, 1998). También en otros estreses abióticos, la prolina es importante para mantener el equilibrio osmótico y protección de membranas (Hoekstra et al., 2001). La figura 3 presenta los resultados de las mediciones de prolina en las plántulas de maíz en temperatura de $5^{\circ} \mathrm{C}$ y $25^{\circ} \mathrm{C}$.

Los resultados indican un aumento significativo del contenido de prolina en las plantas de maíz, cuando estas presentan altas temperaturas nocturnas acumuladas. La prolina y otros compuestos como glutamato, glicina-betaina, carnitina, manitol, sorbitol, fructano, polioles, sacarosa y oligosacáridos se presentan en diferentes condiciones de estrés para realizar un ajuste osmótico junto con iones inorgánicos como $\mathrm{K}^{+}$(Sánchez y Aguirreolea, 2000; Carpenter y Crowe, 1988; Sakai y Larcher, 1987; Levitt, 1980; Rudolph y Crowe, 1985). Este ajuste osmótico, produce un movimiento de agua de un alto potencial hídrico a un bajo potencial hídrico en la célula, manteniendo el turgor en la hoja (Xin y Browse, 1998). También se conoce que el grupo hidroxilo de los azúcares sustituye en los alcoholes el grupo $\mathrm{OH}$ 


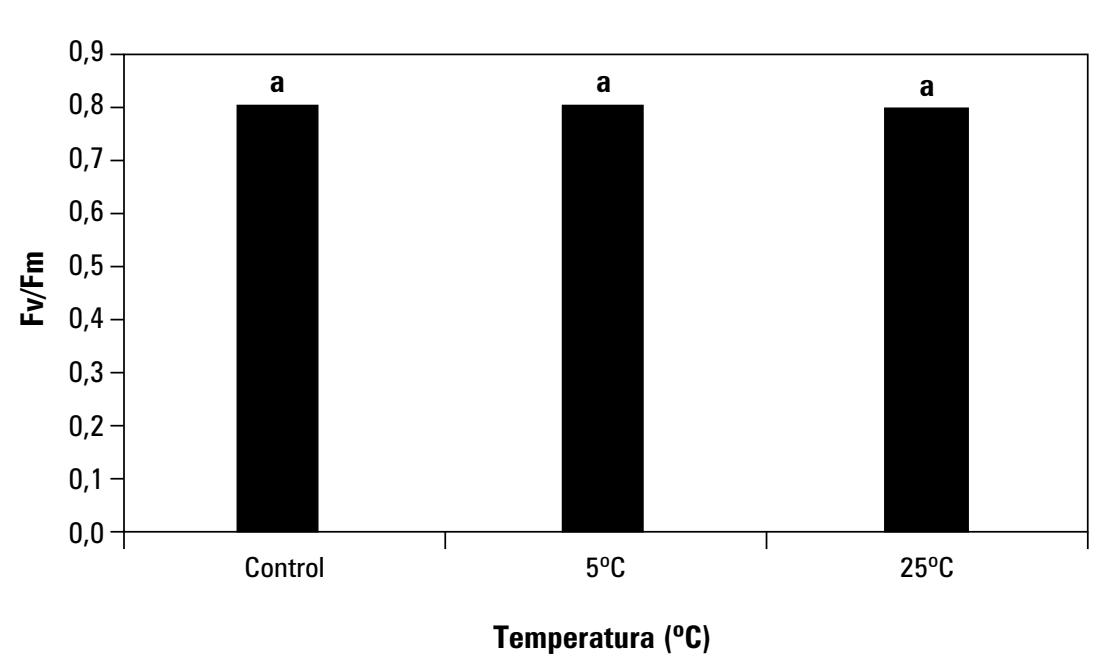

Figura 2. Fluorescencia de la clorofila a medida como Fv/Fm en plantas de maíz (Zea mays L.) en la etapa V3 bajo condiciones de estrés por temperaturas extremas. Control: temperatura nocturna normal $\left(15^{\circ} \mathrm{C}\right)$, frío: temperatura nocturna acumulada por 36 $\mathrm{h}$ de $5^{\circ} \mathrm{C}$, calor: temperatura nocturna acumulada por $36 \mathrm{~h}$ de $25^{\circ} \mathrm{C}$. Promedios con letras distintas indican diferencia significativa según la prueba de Tukey $(P \leq 0.05)$.

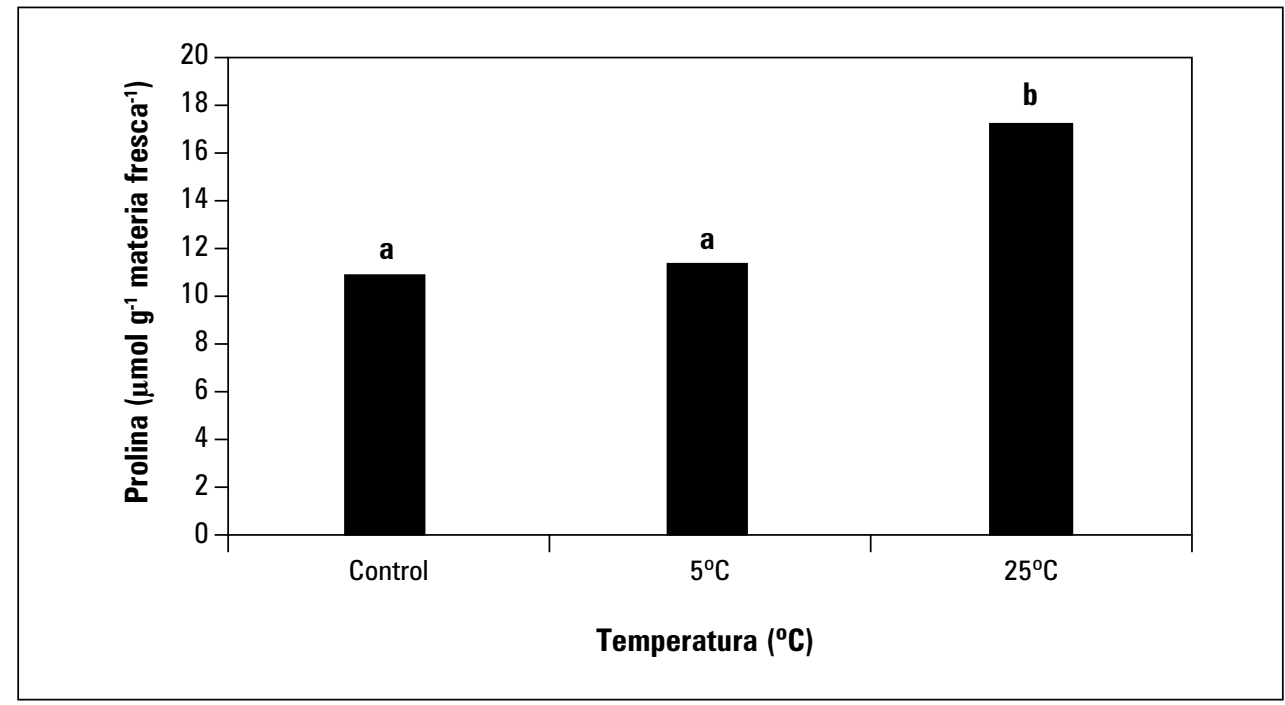

Figura 3. Prolina en plantas de maíz (Zea mays L.) en la etapa V3 bajo condiciones de estrés por temperaturas extremas. Control: temperatura nocturna normal $\left(15^{\circ} \mathrm{C}\right)$, frío: temperatura nocturna acumulada por $36 \mathrm{~h}$ de $5^{\circ} \mathrm{C}$, calor: temperatura nocturna acumulada por $36 \mathrm{~h}$ de $25^{\circ} \mathrm{C}$. Promedios con letras distintas indican diferencia significativa según la prueba de Tukey $(P \leq 0.05)$.

del agua, para mantener las interacciones hidrófilicas con los lípidos de membranas y proteínas, función importante para conservar la integridad estructural de las membranas de la célula (Mahajan y Tuteja, 2005).
El mantenimiento de la integridad de las membranas celulares en este experimento fue encontrado en las plantas de maíz bajo alta temperatura $\left(25^{\circ} \mathrm{C}\right)$, tal cual lo muestra la figura 1 , donde la pérdida de electrolitos en el tratamiento de calor 
no presentó diferencias significativas en comparación al tratamiento testigo, resultados que sugieren un efecto positivo del aumento del aminoácido prolina bajo alta temperatura (figura 3) para conservar la integridad estructural de membranas de citoplasma, mitocondria y cloroplasto en las plantas de maíz. A pesar de no existir diferencias entre el "-control-" y la temperatura baja de $5^{\circ} \mathrm{C}$, sí fue observado un aumento del $4,3 \%$ en la producción de prolina del maíz cuando fue sometido a temperatura baja en comparación con plántulas control.

\section{Malondialdehído (MDA)}

El MDA es un compuesto producido por la peroxidación de lípidos durante el estrés oxidativo. El desajuste del estado redox celular da lugar a la aparición de especies reactivas de oxígeno, como $\mathrm{O}_{2}^{--}, \mathrm{H}_{2} \mathrm{O}_{2}, \mathrm{OH}^{-}$y diversos radicales orgánicos, que provocan daños irreversibles en sustancias vitales para el funcionamiento celular como son proteínas y ácidos nucleícos (Hernández y Sanz, 2008). La peroxidación de lípidos es un proceso complejo que implica la formación y propagación de radicales lipídicos, la toma de oxígeno $y$ un reordenamiento de los dobles enlaces en los lípidos insaturados (Gong et al., 2001). Entre los lípidos afectados se pueden encontrar lípidos complejos presentes en membranas biológicas, lo que puede provocar pérdida de su funcionalidad (Serkan, 2012). Como consecuencia de la oxidación de dichos lípidos, se acumula MDA y otros productos de ruptura, como endoperóxidos, alcoholes, cetonas, aldehídos y éteres (Hansen y Dörffling, 1999). El MDA, formado de la ruptura de ácidos grasos insaturados, sirve como un índice adecuado para determinar el daño oxidativo causado en las células (Hernández y Sanz, 2008). La figura 4 presenta los resultados de MDA producido en las plántulas de maíz bajo condiciones de temperaturas bajas y altas.

Los resultados indican que las temperaturas de $5^{\circ} \mathrm{C}$ y $25^{\circ} \mathrm{C}$ no ejercen un efecto significativo sobre la peroxidación de membranas celulares después de 3 días acumulados de temperaturas altas o bajas en las plantas de maíz. Las plantas responden a los estreses abióticos con mecanismos similares como el incremento de enzimas y compuestos antioxidantes para proteger las membranas celulares y organelos de los efectos dañinos de las especies reactivas de oxígeno (ROS) (Serkan, 2012). La figura 4 puede ser una expresión de una efectiva respuesta antioxidante al estrés por temperaturas en las plantas de maíz al incrementar los niveles de enzimas antioxidantes como la superóxido dismutasa (SOD), guaiacol peroxidasa (POX), ascorbato peroxidasa (APX), glutatión reductasa (GR) y catalasa (CAT), sumado al aumento de compuestos antioxidantes como ascorbato (AsA), glutatión (GSH), prolina y carotenoides, que evitaron la peroxidación de membranas y acumulación de MDA a niveles superiores significativos. Los estudios de Serkan (2012) mostraron en plántulas de maíz una respuesta antioxidante bajo estrés por frío medida en aumentos de la actividad enzimática de la SOD, CAT, APX, GR y los compuestos antioxidantes AsA y GSH. También fue encontrado en el mismo trabajo un incremento del osmorregulador prolina. En los resultados para las plántulas de maíz variedad Porva, el nivel de prolina fue superior bajo altas $(+57,6 \%)$ o bajas $(+4,3 \%)$ temperaturas en comparación con el tratamiento control, incluso con diferencias significativas del nivel alto de prolina en las plántulas de maíz expuestas a $25^{\circ} \mathrm{C}$ frente al testigo o control. El incremento de prolina en plantas ha sido reportado como un mecanismo para aumentar la integridad estructural de membranas celulares (Mahajan y Tuteja, 2005). Un aumento de la integridad en membranas está asociado a una menor peroxidación lipídica y generación de subproductos de la misma como MDA (Duchoslav y Fracheboud, 1994; Lynch, 1990). El incremento de la prolina en las plántulas de maíz sometidas a bajas y altas temperaturas, sugiere la función positiva del aminoácido en la limitación de la peroxidación lipídica de membranas y generación de MDA. 


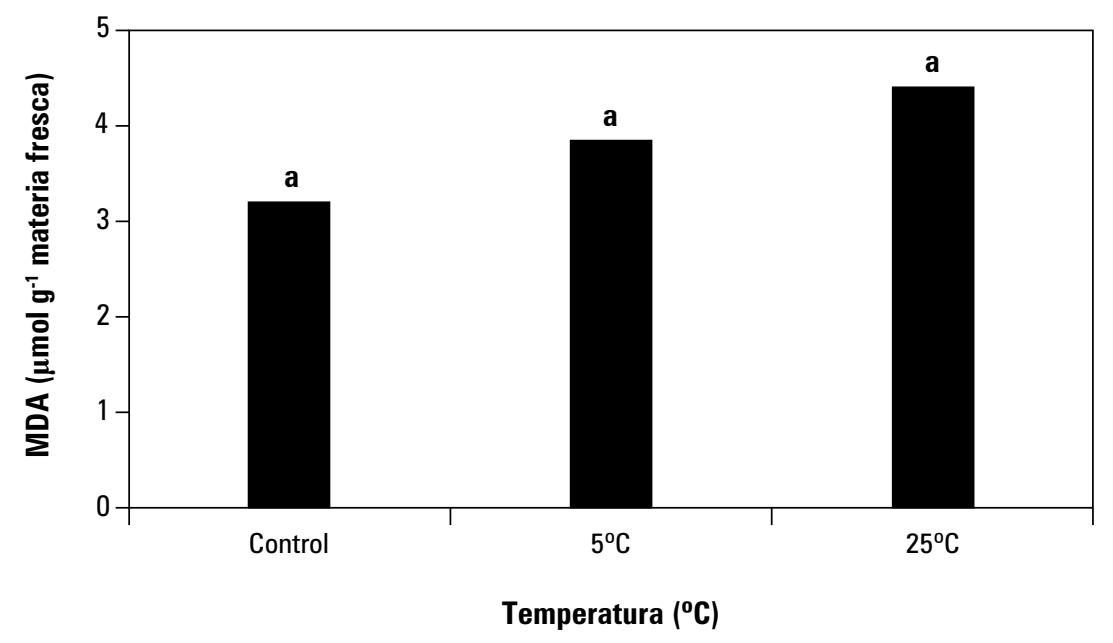

Figura 4. Malondialdehído (MDA) en hojas de plantas de maíz (Zea mays L.) en la etapa V3 bajo condiciones de estrés por temperaturas extremas. Control: temperatura nocturna normal $\left(15^{\circ} \mathrm{C}\right)$, frío: temperatura nocturna acumulada por $36 \mathrm{~h}$ de $5^{\circ} \mathrm{C}$, calor: temperatura nocturna acumulada por $36 \mathrm{~h}$ de $25^{\circ} \mathrm{C}$. Promedios con letras distintas indican diferencia significativa según la prueba de Tukey $(P \leq 0.05)$.

\section{CONCLUSIÓN}

El estudio de la influencia de altas y bajas temperaturas nocturnas en maíz variedad Porva, muestra que la prolina es un aminoácido que podría estar involucrado en la conservación de la integridad de las membranas celulares de las hojas. La integridad de las membranas celulares en las hojas por una acumulación de prolina podría explicar la estabilidad en la fluorescencia de la clorofila y producción de MDA en las plántulas de maíz sometidas a temperaturas extremas de frío o calor. Los resultados de pérdida de electrolitos en temperaturas bajas sugieren una mayor sensibilidad de las plántulas de maíz variedad Porva al estrés por frío, indicando que bajo condiciones de heladas comunes en clima frío $(\geq 2.000$ msnm) en Colombia en ciertos periodos del año, las membranas celulares pueden ser el primer componente estructural afectado en las hojas del maíz. Este trabajo es una guía para encontrar prácticas agronómicas en maíz para regiones frías del país que inhiban la peroxidación de membranas celulares en épocas de heladas.

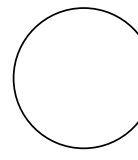

AGRADECIMIENTOS

Se agradece a la Universidad Nacional de Colombia, Facultad de Agronomía, en Bogotá, por el financiamiento de esta investigación. También al profesor Guido Plaza, Director del Laboratorio de Malherbología, Alefsi David Sánchez, estudiante de Ing. Agronómica y Rafael Cruz, técnico de Laboratorio en Fisiología Vegetal. 


\section{REFERENCIAS BIBLIOGRÁFICAS}

Aloni, R. y M. Griffith. 1991. Xylem in the root: shoot junction of cereals. Planta 184, 123-129.

Aroca, R., J. José, M. Irigoyen y D. Sánchez. 2001. Photosynthetic characteristics and protective mechanisms against oxidative stress during chilling and subsequent recovery in two maize varieties differing in chilling sensitivity. Plant Sci. 161, 719-726.

Carpenter, J. y J. Crowe. 1988. The mechanism of cryoprotection of proteins by solutes. Cryobiology 25, 244-255.

Capell, B. y K. Dörffling. 1993. Genotype-specific differences in chilling tolerance of maize in relation to chilling-induced changes in water status and abscisic acid accumulation. Physiol Plant. 88, 638-646.

Duchoslav, S. y Y. Fracheboud. 1994. Influence of chilling stress on the water status of maize seedlings. pp. 617-623 En: Dörffling, K. (ed.). Agriculture: Crop adaptation to cool climates: research progress. European Commission, Bruselas.

Eagles, H. y J. Lothrop. 1994. Highland maize from Central Mexico - its origin, characteristics, and use in breeding programs. Crop Sci. 34, 11-19.

Federación Nacional de Cerealeros de Colombia (Fenalce). 2010. El cultivo de maíz historia e importancia. El cerealista, Mayo-Junio 2010. pp. 10-19.

Flores-Nimedes, A., K. Dörffling y B. Vergara. 1993. Improvement of chilling resistance in rice by application of an abscisic acid analog in combination with the growth retardant tetcyclacis. J Plant Growth Regul. 12, 27-34.

Foyer, C., H. Vanacker, L. Gomez y J. Harbinson. 2002. Regulation of photosynthesis and antioxidant metabolism in maize leaves at optimal and chilling temperatures: review. Plant Physiol. Biochem. 40, 659-668.

Foyer, C. y J. Harbinson. 1994. Oxygen metabolism and the regulation of photosynthetic electron transport. pp. 1-42. En: Foyer, C.H. y P.M. Mullineaux (eds.). Causes of photooxidative stress and amelioration of defense systems in plants. CRC Press, London.

Foyer, C. y J. Harbinson, Relationships between antioxidant metabolism and carotenoids in the regulation of photosynthesisin. pp. 305-325. En: Frank, H.A., A.J. Young, G. Britton y R.J. Cogdell (eds.). The photochemsitry of carotenoids. Kluwer Academic Publishers, The Netherlands.

Franciszek, J., M. Britta y D. Karl. 2002. Importance of abscisic acid for chilling tolerance of maize seedlings. J. Plant Physiol. 159, 635-643.

Gong, M., B. Chen, Z. G. Li y L. H. Guo. 2001. Heatshock-induced cross adaptation to heat, chilling, drought and salt stress in maize seedlings and involvement of $\mathrm{H}_{2} \mathrm{O}_{2}$. J. Plant Physiol. 158, 11251130.

Hansen, H. y K. Dörffling. 1999. Changes in free and conjugated abscisic acid and phaseic acid in xylem sap of drought-stressed sunflower plants. J Exp Bot. 50, 1599-1605.

Hernández, L. y S. Sanz. 2008. Módulo estrés oxidativo y salinidad. En: Laboratorio de Fisiología vegetal avanzada, www.uam.es/docencia/LAvanFis/guiones/guionEOS.pdf; consulta: mayo de 2013.

Hoekstra, F., E. Golovina y J. Buitink. 2001. Mechanisms of plant desiccation tolerance. Trends Plant Sci. 6, 431-438.

Ishitani, M., J. Liu, U. Halfter, C. Kim, W. Shi y J. Zhu. 2000. SOS3 function in plant salt tolerance requires $\mathrm{N}$-myristoylation and calcium binding. Plant Cell 12, 1667-1677.

Janowiak, F. y K. Dörffling. 1996. Chilling of maize seedlings: changes in water status and abscisic acid content in ten genotypes differing in chilling tolerance. J. Plant Physiol. 147, 582-588.

Jorgensen, J. y H. Nguyen. 1995. Genetic analysis of heat shock proteins in maize. Theor. Appl. Genet. 91, 38-46.

Levitt, J. 1980. Responses of plants to environmental stress. chilling, freezing and high temperature stresses. Academic Press, New York, NY.

Li, P. 1994. Maize chilling tolerance induction. pp. 579594 En: Dörffling, K. (ed.). Agriculture: Crop adaptation to cool climates: research progress. European Commission, Bruselas.

Ludewig, M. K. Dörffling y H. Seifert. 1988. Abscisic acid and water transport in sunflower. Planta 175, 325-333.

Lynch, D. 1990. Chilling injury in plants: the relevance of membrane lipids. pp. 17-34. En: Katterman, F. 
(ed.). Environmental injury to plants, Academic Press, New York, NY.

Mahajan, S. y N. Tuteja. 2005. Cold, salinity and drought stresses: An overview. Arch. Biochem. Biophys. 444, 139-158.

Miedema, P. 1982. The effects of low temperature on Zea mays. Adv. Agron. 35, 93-129.

Paulsen, G.M. 1994. High temperature responses of crop plants. pp. 365-389 En: Boote, K.J., J.M. Bennett, T.R. Sinclair y G.M. Paulsen (eds.). Physiology and determination of crop yield. American Society of Agronomy, Madison, WI.

Pollock, C., C. Eagles, C. Howarth, P. Schunmann y J. Stoddard. 1993. Temperature stress. pp. 109-132. En: Fowden, L., T. Mansfield y J. Stoddart (eds.). Plant adaptation to environmental stress. Chapman-Hall, New York, NY.

Rudolph, A. y J. Crowe. 1985. Membrane stabilization during freezing: the role of two natural cryoprotectants, trehalose and proline. Cryobiology 22, 367-377.

Sakai, A. y W. Larcher. 1987. frost survival of plants: Responses and adaptation to freezing stress. Springer-Verlag, Berlin.

Sanchez, M. y J. Aguirreolea. 2000. Transporte de agua y balance hídrico en la planta. pp. 45-64. En: Azcon-Bieto, J. y M. Talón (eds.). Fundamentos de fisiología vegetal. McGraw-Hill-Interamericana de España, Madrid.
Serkan, E. 2012. Androsterone-induced molecular and physiological changes in maize seedlings in response to chilling stress. Plant Physiol. Biochem. $57,1-7$.

Squire, G. 1990. The physiology of tropical crop production. CAB International, Oxon, UK.

Tantau, H. y K. Dörffling. 1991. Effects of chilling on physiological responses and changes in hormone levels in two Euphorbia pulcherrima varieties with different chilling tolerance. J Plant Physiol. 138, 734-740.

Tollenaar, M., D. McCullough y L. Dwyer. 1993. Physiological basis of the genetic improvement of corn. pp. 183-236. En: Slafer, G.A. (ed.). Genetic improvement of field crops. M. Dekker, New York, NY.

Wardlaw, I.F. 1993. Temperature effects on source-sink relationships: a review. En: Kuo, G. (ed.). Adaptation of food crops to temperature and water stress. Proc. Int. Symp.13-18 Aug. 1992. Asian Vegetable Research and Development Center. Taipei, Taiwan.

Xin, Z. 1998. Eskimo1 mutants of Arabidopsis are constitutively freezing tolerant. Proc. Natl. Acad. Sci. USA 95, 7799-7804.

Zhu, J.K. 2002. Salt and drought stress signal transduction in plants. Annu. Rev. Plant Physiol. Plant Mol. Biol. 53, 247-273. 